\title{
E-cigarette use and cigarette smoking initiation studies: A word of caution
}

\author{
Red Thaddeus D. Miguel', Isabella Steffensen'
}

\section{Dear Editor,}

In a recent review, published in Tobacco Prevention \& Cessation, entitled: 'Is adolescent e-cigarette use associated with smoking in the United Kingdom?: A systematic review with meta-analysis', Aladeokin and Haighton ${ }^{1}$ examined the possible relationship between e-cigarette use and initiation of cigarette smoking in the UK. In their meta-analysis of three longitudinal studies ${ }^{2-4}$, the authors found an unusually large pooled odds ratio (OR) of 26.01 (95\% CI: 5.35-126.44). On close examination it is revealed that the very large OR is in fact erroneous and has resulted by entering as log odds the published adjusted ORs from the three longitudinal studies in their generic inverse variance meta-analysis ${ }^{5,6}$. Thus, the ORs being pooled were exponentiated values of the ORs from the studies $^{7}$. Correcting this error shows that the OR remains significant ( $O R=3.86$; $\mathrm{p}<0.00001$ ) (Figure 1) but much lower than the published OR value of 26.01.

It is noteworthy that this amended meta-analysis has a lower pooled OR (3.86) than the meta-analysis of unadjusted ORs by Aladeokin and Haighton $(\mathrm{OR}=5.55)^{1}$. This finding may suggest that controlling for confounders can significantly impact on the outcomes of studies examining the relationship between e-cigarette use and initiation of cigarette smoking. A report by McNeill et al. ${ }^{8}$, synthesising evidence investigating e-cigarette use and its association with initiation of cigarette smoking among adolescents in the UK, supports the importance of controlling for variables in e-cigarette studies ${ }^{8}$. The report found that although e-cigarette users were more likely than non-users of e-cigarettes to try cigarette smoking, there was no established evidence to suggest progression to cigarette smoking. In reaching the foregoing conclusion, McNeill et al. ${ }^{8}$ cited two of the three studies used by Aladeokin and Haighton, viz Conner et al. ${ }^{2}$ and Best et al. ${ }^{3}$, and suggested that these studies were challenged by their inability to properly control for all relevant confounders, which limited their capacity to determine causality ${ }^{8}$.

Until further studies are conducted, evidence linking e-cigarette use to cigarette smoking initiation must be interpreted with caution.

Figure 1. Meta-analysis based on adjusted odds ratios

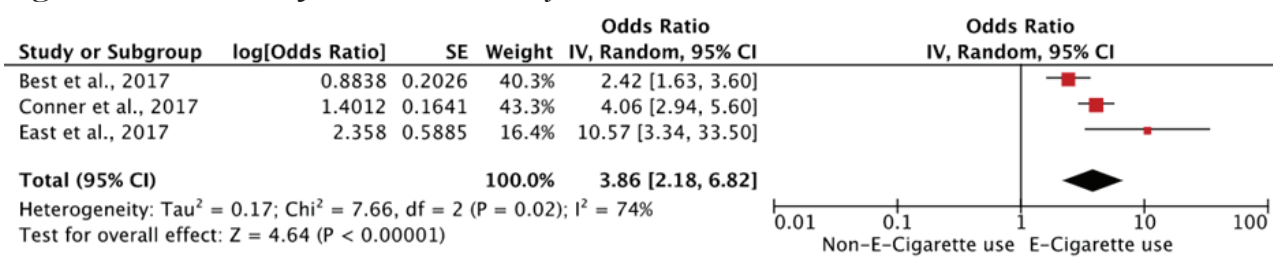




\section{REFERENCES}

1. Aladeokin A, Haighton C. Is adolescent e-cigarette use associated with smoking in the United Kingdom?: a systematic review with meta-analysis. Tob Prev Cessation. 2019;5(April):1-13. doi:10.18332/tpc/108553

2. Conner M, Grogan S, Simms-Ellis R, Flett K, Sykes-Muskett B, Cowap L. Do electronic cigarettes increase cigarette smoking in UK adolescents? Evidence from a 12-month prospective study. Tob Control. 2017;27(4):365-372. doi:10.1136/tobaccocontrol-2016-053539

3. Best C, Haseen F, Currie D, et al. Relationship between trying an electronic cigarette and subsequent cigarette experimentation in Scottish adolescents: a cohort study. Tob Control. 2017;27(4):373-378. doi:10.1136/tobaccocontrol-2017-053691

4. East K, Hitchman SC, Bakolis I, Williams S, Cheeseman H, Arnott D, McNeill A. The Association between Smoking and Electronic Cigarette Use in a Cohort of Young People. J Adolesc Health. 2018;62(5):539-547. doi:10.1016/j.jadohealth.2017.11.301

5. Cleophas TJ, Zinderman AH. Meta-analysis. Circulation. 2007;115(22):2870-2875. doi:10.1161/CIRCULATIONAHA.105.594960

6. Higgins JPT, Green S. Cochrane Handbook for Systematic Reviews of Interventions Version 5.1.0. The Cochrane Collaboration, 2011. www.handbook.cochrane.org. Updated March 2011. Accessed September 18, 2019.

7. Norton EC, Dowd BE. Log Odds and the Interpretation of Logit Models. Health Serv Res. 2018;53(2):859-878. doi:10.1111/1475-6773.12712

8. McNeil A, Brose L, Calder R, Bauld L, Robson D. Evidence review of e-cigarette and heated tobacco products 2018: A report commissioned by Public Health England. London: Public Health England; 2018. https://assets.publishing.service. gov.uk/government/uploads/system/uploads/attachment_data/file/684963/Evidence_review_of_e-cigarettes_and_ heated_tobacco_products_2018.pdf. Accessed September 18, 2019.

CONFLICTS OF INTEREST

The authors have each completed and submitted an ICMJE form for disclosure of potential conflicts of interest. The authors declare that they have no competing interests, financial or otherwise, related to the current work. Both authors report services from RAI Services Company, during the conduct of the study.

\section{FUNDING}

This research was sponsored by RAI Services Company. RAI Services Company had no role in the conception, analysis and writing of the present work or the decision to publish it.

PROVENANCE AND PEER REVIEW

Not commissioned; internally peer reviewed. 